\title{
DECISÕES JUDICIAIS EM AÇÃO CIVIL PÚBLICA QUE TRATA DE POLÍTICAS PÚBLICAS: POSSIBILIDADE DE INTERVENÇÃO JUDICIAL E SEUS LIMITES
}

\author{
Loren Tazioli Engelbrecht Zantut ${ }^{*}$ \\ Paulo de Tarso Brandão**
}

\begin{abstract}
RESUMO
O presente artigo busca verificar os fundamentos para a legitimação do juiz para interferir ou definir políticas públicas pela via da ação civil pública que versa sobre direitos difusos, coletivos em sentido estrito e individuais homogêneos, analisando a tendência das tomadas de decisão judicial neste âmbito. Para alcançar o resultado da pesquisa, utilizou-se pesquisa bibliográfica e jurisprudencial, buscando traçar uma linha de comportamento dos entendimentos sobre do tema.
\end{abstract}

PALAVRAS-CHAVE: judicialização; direitos coletivos; ação civil pública; garantias.

\begin{abstract}
This article seeks to verify the grounds for legitimizing judicial decisions in public civil action that deals with diffuse, collective rights in the strict sense and individual homogeneous, analyzing the trend of judicial decision making in this scope. In order to achieve the result of the research, we used bibliographical and jurisprudential research, seeking to draw a line of understanding behavior on the subject.
\end{abstract}

KEYWORDS: judicialization; collective rights; public civil action; guarantees.

\footnotetext{
* Mestranda bolsista PROSUP-CAPES no Programa de Pós-Graduação Stricto Sensu em Ciências Jurídicas da Universidade do Vale do Itajaí-UNIVALI - SC. Email: lohengel@hotmail.com.

** Doutor em Direito pela Universidade Federal de Santa Catarina, Procurador de Justiça do Ministério Público do Estado de Santa Catarina, Professor do Programa de Pós-graduação Stricto Sensu em Ciência Jurídica da Universidade do Vale do Itajaí - UNIVALI em seus cursos de Doutorado e Mestrado em Ciência Jurídica. Itajaí/Sc-Brasil. Endereço Eletrônico: brandao@floripa.com.
} 


\section{INTRODUÇÃO}

Busca-se verificar os fundamentos para a legitimação do juiz para interferir ou definir políticas públicas pela via da ação civil pública que versa sobre direitos difusos, coletivos em sentido estrito e individuais homogêneos, analisando a tendência das tomadas de decisão judicial neste âmbito.

Para tanto, através de levantamento bibliográfico e jurisprudencial, foram traçados os conceitos sobre referidos interesses - difuso, coletivo e individual homogêneo.

Após, será abordada a ação civil pública, a fim de entender o mecanismo processual e material deste tipo de ação coletiva para a garantia dos interesses anteriormente comentados.

Por fim, serão apresentados os fundamentos sobre a intervenção judicial nas políticas públicas em ação civil pública, trazendo alguns exemplos relevantes no Brasil.

\section{DIREITOS DIFUSOS, COLETIVOS E INDIVIDUAIS HOMOGÊNEOS}

Para analisar os fundamentos e o posicionamento contemporâneo sobre a busca pela preservação dos direitos coletivos latu sensu, faz-se necessária, a priori, conceituar tais direitos ou interesses, contextualizando-os na história.

Os direitos ou interesses difusos, coletivos e individuais homogêneos sempre existiram, mas a preocupação doutrinária e legislativa em identifica-los e protege-los nos últimos anos foi bastante acentuada. Segundo Mazzilli:

A razão consiste em que a defesa judicial de interesses transindividuais de origem comum tem peculiaridades: não só esses interesses são intrinsecamente transindividuais, como também sua defesa judicial deve ser coletiva, sejam em benefício dos lesados, seja ainda em proveito da ordem jurídica. Dessa forma, o legislador estipulou as regras próprias sobre a matéria, especialmente para solucionar problemas atinentes à economia processual, à legitimidade ativa, à destinação do produto da indenização e aos efeitos da imutabilidade da coisa julgada. 
No mesmo sentido, Ferraz, Milaré e Nery Jr. afirmam em sua clássica obra que os: "interesses difusos ou coletivos existiram sempre, desde que o homem passou a viver em grupo, em sociedade, uma vez que são conaturais a esta. A sociedade moderna, entretanto, colocou-os em maior evidência".

Ainda tratando da evolução desses interesses, Mancuso afirma que se iniciou com os interesses "individuais" - de captação e fruição por um indivíduo isoladamente -, passando para os interesses "sociais" - interesses pessoais do grupo visto como pessoa jurídica), passando, então, nos interesses "coletivos" - os quais ultrapassam as esferas anteriores, restringindo-se a grupo de pessoas bem definido -, passando a ser interesse "geral" ou "público" - a coletividade representada pelo Estado (o bem comum, segurança pública, saúde pública, etc. No entanto, há um último grau nessa escala, os direitos "difusos".

Desde então, os precursores nos estudos dos direitos metaindividuais - o italiano Mauro Capeletti e o americano Bryant Garth - e a doutrina processual vêm desenvolvendo grande esforço para um efetivo acesso à justiça, dentre eles com a representação dos direitos difusos.

No Brasil, a Lei $n^{\circ}$ 8.078/1990 disciplinando o Código de defesa do Consumidor, mais precisamente em seu art. 81, parágrafo único, I, II e III, determina qual deve ser o perfeito entendimento dos termos direitos ou interesses difusos, coletivos e individuais homogêneos.

Frise-se que é pacificado na doutrina que: "é vazio de significado prático a discussão em torno dos termos interesse e direito, devendo ser entendidos como indicativos da mesma situação, qual seja, a relação entre um sujeito e um grupo de sujeitos, determinados ou não, diante de um bem".

Extrai-se do referido dispositivo:

Art. 81. A defesa dos interesses e direitos dos consumidores e das vítimas poderá ser exercida em juízo individualmente, ou a título coletivo.

Parágrafo único. A defesa coletiva será exercida quando se tratar de:

I - interesses ou direitos difusos, assim entendidos, para efeitos deste código, os transindividuais, de natureza indivisível, de que sejam titulares pessoas indeterminadas e ligadas por circunstâncias de fato; II - interesses ou direitos coletivos, assim entendidos, para efeitos 
deste código, os transindividuais, de natureza indivisível de que seja titular grupo, categoria ou classe de pessoas ligadas entre si ou com a parte contrária por uma relação jurídica base;

III - interesses ou direitos individuais homogêneos, assim entendidos os decorrentes de origem comum.

Os interesses difusos e coletivos em sentido estrito, são transindividuais. O termo transindividual, por si só, já se mostra suficiente para indicar tudo aquilo que vai além, trans + individual, aquilo que ultrapassa o indivíduo.

Os interesses transindividuais (também conhecidos como interesses coletivos, em sentido lato) estão situados em posição intermediária entre o interesse público e o privado, vez que são compartilhados por grupos, classes ou categorias de pessoas. São interesses que excedem o âmbito estritamente individual, mas não chegam propriamente a constituir interesse público.

Inicialmente, quanto ao direito difuso, tem-se que:

Especificamente no caso do interesse difuso, tem-se a situação de indeterminação dos seus sujeitos, situação sem limites. Desse modo, apesar de uma sociedade ser formada por sujeitos individualizados, é possível que se deparem com situações em que todos serão atingidos de alguma forma, existe portanto o interesse individual envolvido, não se tem dúvida sobre esse ponto, porém há também um ponto comum entre todos. Quando esse ponto comum se mostra indivisível, pertence a todos, indiscriminadamente, estar-se-á diante de interesse difuso.

Mazzilli adverte que, não obstante o Código de Defesa do Consumidor faça referência a uma situação fática o elo comum dos lesados que compartilhem os mesmos direitos difusos, é clarividente que referida situação fática também se subordina a uma relação jurídica, porém, a lesão não será decorrente diretamente da relação jurídica em si, mas sim da situação fática resultante.

Exemplifica Mazzilli:

(...) um dano ambiental que ocorra numa região envolva tanto uma situação fática comum como uma relação jurídica incidente sobre a hipótese; mas o grupo lesado compreende apenas os moradores da 
região atingida - e, no caso, esse será o elo fático que caracterizará o interesse difuso do grupo.

(...) uma propaganda enganosa pela televisão relaciona-se, sem dúvida, com questões fáticas e jurídicas; contudo, o que reúne o grupo para fins de proteção difusa é o fato de seu acesso efetivo ou potencial à propaganda enganosa.

Caldeira resume que os elementos de caracterização dos interesses difusos são dois, a indivisibilidade do interesse envolvido e a presença desse interesse a um gama indeterminável de sujeitos.

Por sua vez, Mancuso elenca as características básicas dos direitos difusos como: "indeterminação dos sujeitos; indivisibilidade do objeto; intensa conflituosidade; duração efêmera, contingencial".

Quanto a indeterminação dos sujeitos, questiona Mazzilli, como seria possível individualizar as pessoas lesadas com o derramamento de óleo na Baía da Guanabara, ou com a devastação da Floresta Amazônica? Como determinar exatamente quais as pessoas lesadas em razão de terem acesso a uma propaganda enganosa, divulgada pelo rádio ou pela televisão? A resposta é que não é possível, o que demonstra o caráter indivisível do interesse difuso.

Para Souza “(...) o conceito de indeterminação reside na impossibilidade matemática de fixarmos exatamente o número de pessoas atingidas por um fato - sem embargo de tal contingente poder ser estimado por meio, v. g., de censos demográficos".

Outra característica é a indivisibilidade do objeto, sendo definida por Souza de forma paradoxal, como o direito pertencente a todos e a ninguém ao mesmo tempo, pois as pessoas indetermináveis possuem certo direito que lhes é comum, no entanto não se pode identificar a parcela dele que cabe para cada uma delas.

Nesta esteira, os interesses indivisíveis, ainda que sejam comuns a certas categorias de pessoas, é impossível afirmar com precisão a quem pertencem, nem em que medida quantitativa são partilhados; entre seus titulares, não há vínculo jurídico.

Esses direitos, de acordo com Mancuso, dá ensejo a posições diversas, de conteúdo fluido - o que a doutrina italiana chama de "intrinsceca conflittualità" e, assim, típica das escolhas políticas. Acrescenta o autor que: 
(...) não se trata de controvérsia envolvendo situações jurídicas definidas (por exemplo, se A se julga credor de B, que resiste aquela pretensão), mas de litígios que têm por causa remota verdadeiras escolhas políticas. Ora, neste campo as alternativas são ilimitadas, porque o favorecimento da posição " $\mathrm{A}$ " irá contrariar interesses da posição "B".

(...) Cabe notar que também certos atos de gestão da coisa pública podem atingir interesses difusos, nos casos em que aqueles atos, por sua natureza, atingem largos segmentos da sociedade, por via mediata ou reflexa.

"Dir-se-ia que, enquanto o interesse geral ou público concerne primordialmente ao cidadão, ao Estado, e às suas mútuas relações, os interesses difusos se reportam ao homem, à nação, à percepção do justo".

Por fim, os direitos difusos apresentam mutação no tempo e no espaço, vez que não se apresentam jungidos a um vínculo jurídico básico, mas a situações contingenciais, e daí deriva a consequência deles serem mutáveis, da mesma forma em que as situações de fato são, podendo ser mudada ou até mesmo desaparecer.

Interesses difusos como a vida, a liberdade, a igualdade, a segurança, a educação, entre outros, mais do que possuírem natureza subjetiva, têm caráter humanístico, social, transindividual, não só permitindo, como impondo sua proteção por meio de ação civil pública, inclusive.

No que pertine os direitos coletivos, cumpre distinguir as expressões de interesses coletivos stricto e latu sensu. Temos que, em sentido lato:

(...) ou seja, mais abrangente, a expressão interesses coletivos referese a interesses transindividuais, de grupo, classes ou categorias de pessoas. Nessa acepção larga é que a Constituição de referiu a direitos coletivos, em seu Título II, ou a interesses coletivos, em seu art. 129, III; ainda nesse sentido é que o próprio CDC disciplina a ação coletiva, que se presta não só à defesa de direitos coletivos stricto sensu, mas também à defesa dos interesses difusos e individuais homogêneos. 
O conceito de direitos coletivos stricto sensu se encontra no art. 81, parágrafo único, inciso II, do CDC:

II - interesses ou direitos coletivos, assim entendidos, para efeitos deste código, os transindividuais, de natureza indivisível de que seja titular grupo, categoria ou classe de pessoas ligadas entre si ou com a parte contrária por uma relação jurídica base;

As peculiaridades dos direitos coletivos são a indivisibilidade do objeto, a determinação dos sujeitos que formam um grupo, categoria ou classe e a existência de um vínculo jurídico ligando os integrantes do grupo entre si ou com a parte contrária.

Neste viés, os interesses coletivos em sentido estrito também têm natureza indivisível - assim como os difusos -, à medida em que não é possível compartilhá-los individualmente entre seus titulares, ou seja, atendido o interesse de um, estará atendido o de todos.

Conclui-se que a distância entre os interesses difusos e coletivos stritu sensu, de acordo com Caldeira, funda-se no fato de que, enquanto os interesses difusos pertencem a sujeitos indetermináveis e a ligação entre os titulares é fática, os coletivos são de sujeitos determináveis e a relação entre os sujeitos é jurídica. $\mathrm{O}$ que há de comum entre esses direitos é a indivisibilidade do bem envolvido.

As fronteiras desses dois interesses - difusos e coletivos estão definitivamente delimitadas, sendo difuso o interesse que abrange número indeterminado de pessoas unidas pelo mesmo fato, enquanto interesses coletivos seriam aqueles pertencentes a grupos e categorias de pessoas determináveis, possuindo uma só base jurídica.

Como denota-se do texto do inciso II, do parágrafo único, do art. 81, constante do CDC, o direito coletivo em sentido estrito se refere a uma relação jurídica básica, a qual é o elo comum entre os lesados que comunguem o mesmo interesse coletivo. No entanto, é preciso admitir que que essa relação jurídica disciplinará inevitavelmente uma situação fática concreta, da qual não decorrerá a lesão. A lesão decorrerá da própria relação jurídica viciada que une o grupo.

Exemplifica-se situação de lesão aos direitos coletivos em sentido estrito: 
Exemplifiquemos com uma cláusula ilegal em contrato de adesão. A ação civil pública que busque a nulidade dessa cláusula envolverá uma pretensão à tutela de interesse coletivo em sentido estrito, pois o grupo atingido estará ligado por uma relação jurídica básica comum, que, nesse tipo de ação, deverá necessariamente ser resolvida de maneira uniforme para todo o grupo lesado.

Ainda, o direito individual homogêneo está previsto no inciso III, do parágrafo único, do art. 81, do Código de Defesa do Consumidor: "III - interesses ou direitos individuais homogêneos, assim entendidos os decorrentes de origem comum".

Em sentido lato, os direitos individuais homogêneos são também interesses coletivos. Em sentido estrito, Souza define os direitos individuais homogêneos como "aqueles que dizem respeito a um número determinado de pessoas, titulares de objetos divisíveis e que estão ligadas entre si por um vínculo fático, decorrente da origem comum das lesões".

Smanio leciona que os titulares dos direitos individuais homogêneos são vários e suas pretensões são idênticas ou parecidas, sendo que o Código de Defesa do Consumidor permitiu expressamente que esses direitos individuais possam ser defendidos coletivamente.

Caldeira exemplifica o interesse individual homogêneo:

Como exemplo de direitos individuais homogêneos poderíamos arrolar situação que infelizmente vem se perpetuando nas relações de consumo, qual seja, a identificação de quantidade menor do que a indicada na embalagem. Nesse caso, poderá perfeitamente o indivíduo atuar isoladamente contra a fabricante como também as associações de defesa do consumidor ou mesmo o Ministério Público por meio das demandas coletivas visando a punir e exterminar tal prática do mercado de consumo.

Outro exemplo ocorreu com a descoberta e posteriormente confissão das fraudes cometidas pelo juiz de futebol Edílson Pereira de Carvalho. Com a anulação dos jogos, aqueles torcedores que adquiriram ingressos para as partidas anuladas tiveram direito de substituí-los por ingressos da partida remarcada devendo comprovar seu direito. Desse modo, como o direito é individual, autônomo, duas vias jurídicas surgem: a) cada torcedor, comprovando aquisição do ingresso para os jogos anulados, poderia promover demanda 
pleiteando a substituição do ingresso; b) o Ministério Público ou as associações destinadas à proteção dos consumidores poderia fazê-lo por meio de ação civil pública.

Não se pode confundir direito individual homogêneo com litisconsórcio - que são várias demandas, com pluralidade subjetiva. Os interesses individuais homogêneos, portanto, é uma só demanda defendendo os interesses de vários indivíduos determináveis. $\mathrm{Ou}$, no dizer de James Marins, os direitos individuais homogêneos possuem uma transcendência científica diferente dos interesses difusos e coletivos porque significam "apenas um trato coletivo a direitos já (e desde sempre) prestigiados por instrumentos individuais de proteção".

Há, assim, interesses que envolvem uma categoria determinável de pessoas - individuais homogêneos e coletivos em sentido estrito - e outros compartilhados por grupo indeterminável de pessoas - interesses difusos.

Para Mazzilli, é nítido que tanto os direitos difusos, quanto os coletivos e individuais homogêneos têm origem em uma relação jurídica comum. No entanto, nos interesses coletivos propriamente ditos a lesão ao grupo provém da própria relação jurídica questionada no objeto da ação coletiva, enquanto nos difusos e nos individuais homogêneos, a relação jurídica é questionada apenas como causa de pedir, buscando reparar um dano fático - indivisível (difusos) ou divisível (individuais homogêneos) .

Passa-se, então, a analisar a ação civil pública para a garantia dos direitos metaindividuais.

\section{A AÇÃo CIVIL PÚBLICA COMO FORMA DE ASSEGURAR A OBSERVÂNCIA DOS DIREITOS DIFUSOS E COLETIVOS}

Todos os direitos de grupos, classes ou categorias de pessoas merecem acesso à Justiça através da tutela coletiva, não bastando apenas a possibilidade da tutela individual. Esse acesso à Justiça por meio da tutela coletiva é exercida pelas ações coletivas.

Nos conflitos difusos o objeto da lide são interesses difusos, coletivos ou individuais homogêneos, além de abarcar interesses macrossociais - grupos, categorias ou classes de pessoas com 
pretensões colidentes entre si.

Ademais, a defesa judicial coletiva faz-se por meio de legitimação ordinária, como explica-se a seguir:

Em síntese, a legitimidade para buscar em Juízo a tutela dos interesses coletivos (abrangendo com tal expressão os interesses coletivos, difusos e individuais homogêneos) decorre de lei. Assim, na esfera da Ação Civil Pública não opera o conceito ou a noção de legitimidade extraordinária, uma vez que as pessoas jurídicas ou as instituições, são legitimadas por força de disposição legal; e, nesse caso, a legitimação é sempre ordinária. Qualquer outra pessoa que não seja legitimada por força de lei não poderá exercitar o direito de ação decorrente da Ação Civil Pública, pois em nenhuma hipótese poderá haver a substituição processual, ou seja, a legitimação extraordinária.

Para Mazzilli é equivocado entender que em ação civil pública ou coletiva somente seja possível discutir uma só espécie de direito transindividual, não é raro serem abordadas mais de uma espécie. Por exemplo, em uma única ação civil pública ou coletiva é possível combater os aumentos ilegais de mensalidades escolares já aplicados aos alunos atuais (direitos coletivos em sentido estrito), buscar repetição de indébito (interesses individuais homogêneos) e, ainda, pedir proibição de aumentos futuros (direitos difusos) .

Desta forma, passa-se à conceituação de ação civil pública.

Afirma Smanio, ao conceituar Ação Civil Pública, que há impropriedade no nome, tendo em vista que toda ação civil é pública, por ser ação é direito de natureza pública. Ainda assim, leciona que ação civil pública (denominada na Lei $\mathrm{n}^{\circ} 7.347 / 85$ e ação coletiva (como é chamada no Código de Defesa do Consumidor) são sinônimas, quando tem por objetivo a tutela de interesses metaindividuais.

Nesta esteira, pode-se entender o direito da ação coletiva como sendo subjetivo - de exercício voluntário -, abstrato - independe de resultado -, autônomo - desvinculado do direito material -, público exercido em face do Estado, e coletivo - pertencente a sujeitos indeterminados (difuso), determinados ou determináveis (coletivo) ou ligados pela mesma situação jurídica comum (individual homogêneo). 
Com observância às leis que disciplinam o microssistema coletivo, observa-se que ação civil pública é qualquer ação movida com base na Lei no 7.347/85 - Lei da Ação Civil Pública -, para a defesa dos interesses transindividuais, seja qual foi o legitimado.

O direito na esfera da Ação Civil Pública não se confunde com a ação no âmbito do Processo Civil, tratando-se de mais do que uma simples modificação conceitual, mas sim de reconhecer que determinados conceitos do Processo Civil não operam na esfera dos interesses coletivos.

Brandão considera importantes fatores históricos quanto a natureza jurídica da Ação Civil Pública:

Em primeiro lugar, foi na esfera do Processo Civil que os estudiosos identificaram o fenômeno dos interesses difusos e coletivos e, mais tarde, dos individuais homogêneos. Não foi, como seria desejável, no âmbito da Teoria Política; por isso o vício de encarar-se a Ação Civil Pública como instituto pertencente à esfera do Processo de cunho intersubjetivo.

O campo de incidência da Ação Civil Pública é muito amplo, como prescreve o art. $1^{\circ}$, da Lei $\mathrm{n}^{\circ} 7.347 / 85$, observando-se um rol exemplificativo, ampliado pelo inciso IV (IV - a qualquer outro interesse difuso ou coletivo).

Leciona Mazzilli que uma análise apressada do art. $1^{\circ}$, da Lei da Ação Civil Pública poderia dar a entender que a ação civil pública somente poderia ter por objeto a responsabilidade por danos materiais e morais a interesses transidividuais. No entanto, esta ação também pode ter por objeto pedido para evitar os danos, pedido cominatório ou qualquer outro pedido para dar eficácia a tutela coletiva.

Em sede constitucional, a ação civil pública encontra-se prescrita no art. 129, inciso III, da CRFB/88: "São funções institucionais do Ministério Público: (...) III - promover o inquérito civil e a ação civil pública, para a proteção do patrimônio público e social, do meio ambiente e de outros interesses difusos e coletivos".

Outro equívoco na interpretação da Lei da Ação Civil Pública diz respeito a tutela dos direitos individuais homogêneos, isso porque referida Lei somente faz menção direta a defesa dos interesses 
difusos e coletivos, nada sobre individuais homogêneos. Sobre o assunto:

Esse entendimento é todo equivocado, pois que, como a LACP e o CDC se integram no tocante à defesa coletiva de interesses transindividuais, também os interesses individuais homogêneos estão alcançados pela proteção da ação civil pública da Lei n. 7.347/85, estejam ou não relacionados com a defesa de grupos de consumidores. Assim, pode ser objeto de ação civil pública ou coletiva a defesa de quaisquer interesses transindividuais, sejam difusos, coletivos ou individuais homogêneos, digam ou não respeito a consumidores.

No entanto, não obstante seja exigida a apresentação de todos estes elementos para o oferecimento do processo coletivo, ao que é dado maior importância é ao pedido, relativizando-se consideravelmente, nesse tipo de ação, a causa de pedir e o polo ativo da demanda.

Assim, após a análise do pedido pelo Magistrado e consequente decisão, da ação civil pública é possível resultar condenação em desfavor do réu, a qual, ao contrário da ação no processo civil, admite condenações genéricas. Referida possibilidade encontra respaldo no art. 95, do Código de Defesa do Consumidor.

Ressalte-se que na tutela coletiva, a destinação do produto da indenização normalmente é especial, sendo que nas ações civis públicas ou coletivas que tratem de interesses difusos e coletivos, o valor proveniente da indenização é posto em um fundo fluido, de utilização flexível na reparação do interesse lesado, enquanto nas que tratem de interesses individuais, o produto destina-se aos lesados.

Ressalte-se que "o fato da condenação ser genérica não lhe retira, porém, o caráter de certeza e liquidez (existência e determinação do objeto)". Assim, para que a coisa julgada em ação civil pública tenha possibilidade de ser executada pelos danos individuais homogêneos, por cada indivíduo, é indispensável que tenha sido pedido expressamente na inicial, pois a imutabilidade erga omnes ou ultra partes da sentença terá direta correspondência ao pedido formulado na ação civil pública.

Assim, após a condenação em indenização pecuniária decorrente do resultado da ação civil pública, a importância é 
destinada para um fundo para reconstituição dos interesses metaindividuais lesados - Fundo de Defesa de Direitos Difusos (FDD) - regulamentado pelo Decreto $\mathrm{n}^{\circ}$ 1.306/94.

A condenação intervém nas políticas públicas, o que leva a questionar-se se, na visão da doutrina e da jurisprudência pátria: há confronto com a tripartição de poderes ou é medida necessária para a garantia dos direitos coletivos não observados, ou observados ineficazmente, pelo Poder Executivo e/ou Legislativo? É o que será analisado a seguir.

\section{A AÇÃO CIVIL PÚBLICA COMO MEIO PARA INTERVENÇÃO JUDICIAL NAS POLÍTICAS PÚBLICAS}

A ação civil pública se presta, além dos demais objetivos, para que os legitimados e, em especial o Ministério Público, tenham condições de questionar políticas públicas, para que os Poderes Públicos e os serviços de relevância pública observem os direitos assegurados pela Constituição da República Federativa do Brasil.

Sobre essa possibilidade e limites, afirma Mazzilli:

Com certeza, não poderá o Ministério Público pedir ao Judiciário que administre no lugar do administrador; contudo, poderá cobrar em juízo a aplicação dos princípios da Administração que possam estar sendo descurados, e, com isso, restaurar a legalidade.

Também não poderá o Ministério Público estar movido por critérios político-partidários; entretanto, sua ação tem inegável caráter político, no sentido técnico da expressão.

Deste modo, conclui-se que os legitimados para propor a Ação Civil Pública têm legitimidade para questionar atos do governo, que, entre outras hipóteses, ferirem o princípio da legalidade, moralidade, eficiência ou configurarem abuso de poder, etc.

Importante salientar o entendimento de Grinover, afirmando que a tendência brasileira do indiscriminado controle do mérito de ato administrativo tem sido condenado pela doutrina e jurisprudência, que estão atentas aos perigos do controle jurisdicional do ato discricionário. Para a autora, neste caso, haveria uma verdadeira substituição da discricionariedade do administrador pela 
do Magistrado, o que inverteria os papeis funcionais do Poder e bloquearia as atividades administrativas.

Em sentido contrário, Mancuso aponta algumas barreiras políticas, vistas por parte da doutrina, que justificam a utilização da Ação Civil Pública para buscar garantir algumas políticas públicas que resguardem os direitos coletivos em sentido lato. A primeira seria o temor da pulverização da autoridade estatal, disseminada entre os grupos portadores de interesses metaindividuais. O segundo trata do acesso direto desses interesses ao centro de decisão (Poder Judiciário), que seria conflitante com o sistema político representativo (Poderes Executivo e Legislativo). Por fim, há receio que pudesse ser desconfigurada a estrutura da trilogia açãojurisdição-processo, o que transformaria o Judiciário de um Superpoder. Com isso, a tripartição dos poderes estaria em risco.

De fato, o acesso aos direitos difusos à justiça, através da ação civil pública e demais ações coletivas, por si só, causa alteração na trilogia "ação-jurisdição-processo", vez que essa estrutura se direciona para dirimir conflitos intersubjetivos e não metaindividuais. Isso é reforçado em razão da eficácia das decisões judiciais na ação civil pública ser erga omnes (art. 102, §2 $2^{\circ}$, da CRFB/88).

No entanto, é reconhecido pela doutrina que a ação civil pública pode ser uma forma de participação comunitária na gestão da coisa pública, em questões em que os Poderes Executivo e Legislativo não estão a tutelar esses interesses, ou o fazem de forma ineficaz. Ainda, importante observar que:

(...) é difícil e complexo o acesso do indivíduo às instâncias administrativa e legislativa: são requerimentos, démarches demoradas, lobbies, etc. Ao passo que, para ter acesso a um juiz togado, é bastante uma petição em forma e figura de juízo.

(...) Não raro, uma associação ambientalista consegue, mercê de uma cautelar preparatória de ação civil pública (Lei 7.347/85, arts. $4^{\circ} \mathrm{e}$ $5^{\circ}$ ), obstar um desmatamento iminente que, de outro modo, acarretaria degradação à cobertura vegetal praticamente irreversível.

No mesmo sentido, Mancuso diz que as vias usuais de recepção dos interesses gerais, isto é, o Executivo e o Legislativo não se mostram satisfatoriamente eficazes, atuando em suas 
estruturas internas como freio ou desestímulo para a espontânea veiculação dos interesses metaindividuais. Além disso, há típica morosidade nos processos decisórios nessas instâncias primárias, estando em descompasso com a celeridade requerida por esses emergentes interesses de massa.

Isso resultou no chamamento do Poder Judiciário para desempenhar um novo papel, "quiçá um rôle suppletif."

Observa-se, então, que parte dominante da doutrina entende que essa judicialização se mostra por vezes necessária, ao passo que o interesse público primário nem sempre coincide com o interesse público secundário, ou seja, nem sempre o interesse da Administração coincide com o efetivo interesse da comunidade, quer pela indisponibilidade dos interesses públicos que, não raro, contrapõem ao interesse geral, quer pelas próprias prioridades que cada administrador, segundo seus planos e metas políticas, busca imprimir nas ações estatais.

De toda forma, o judiciário, em casos de jurisdição coletiva, deve estar bastante atento com o quesito da relevância social do interesse e sua adequada representação nos autos, para prevenir o desvirtuamento da ação coletiva, de outro modo poderia servir como instrumento de "falcatruas multitudinárias". Esse alargamento da seara jurisdicional deve ser feito com prudência, observando os princípios da razoabilidade-proporcionalidade.

Sobre a postura do juiz nos conflitos metaindividuais, Nalini coloca que o Magistrado "não deve ser um revolucionário, a decidir contra legem, trazendo instabilidade ao valor apreciável da segurança jurídica, mas não deve se recusar à outorga, quando o sistema está a mostrar soluções tecnicamente viáveis e politicamente corretas".

Conclui Mancuso que “não se trata de 'inchamento' do Poder Judiciário, porque, quando ele outorga tutela aos interesses metaindividuais, não se está desenvolvendo atividade de 'suplência'; é sua própria atividade, de outorgar tutela a quem merece”.

Assim, já em 1986 constata-se que:

A era do Juiz politicamente neutro, no sentido liberal da expressão, já foi superada. Os juízes deixam de ser, como têm sido até agora, exclusivamente árbitros distantes e indiferentes de conflitos privados 
ou de litígios entre indivíduos e Estado. Doravante, incumbe também à justiça realizar, no seu campo de atividade, os grandes objetivos socioeconômicos da organização constitucional".

Assim, o juiz encontra-se em posição de lidar com valores meta-jurídicos, escolhas primárias, opções políticas, como, por exemplo, com questões envolvendo o manejo de bens ambientais, a aplicação dos recursos públicos, e qualquer outro aspecto que concerne à larga extensão da qualidade de vida.

Explora-se a seguir casos práticos de ações civis públicas com decisões judiciais que interferiram em políticas públicas.

\subsection{Casos práticos de intervenção judicial em políticas públicas através da ação civil pública}

Os casos práticos abordados abaixo poderão permitir a análise da tendência do atual perfil do judiciário em ações coletivas que buscam garantir a aplicação e a eficácia dos direitos coletivos em sentido lato.

Primeiramente, colhe-se da jurisprudência do Tribunal Regional Federal da $4^{\text {a }}$ Região o seguinte entendimento:

ADMINISTRATIVO. APELAÇÃO CÍVEL. AÇÃO CIVIL PÚBLICA. CRIAÇÃO DE VAGAS DESTINADAS AO RECOLHIMENTO DE PRESOS NOS REGIMES FECHADO E SEMIABERTO NO ÂMBITO DO SISTEMA CARCERÁRIO DO ESTADO DE SANTA CATARINA. - Excluído da apreciação judicial o pedido sucessivo que visa a assegurar aos condenados com direito à progressão de regime a espera de vagas em prisão domiciliar, enquanto aguardam o aparecimento de vaga no regime semiaberto, por se tratar de competência exclusiva do juízo das execuções penais. - Afastadas asa preliminares de ilegitimidade passiva da União, inadequação da ação civil pública, impossibilidade jurídica do pedido e perda de objeto. - A superlotação e o obstáculo à progresso de regime afrontam de forma clara o princípio da dignidade da pessoa humana, além de retirar do sistema de progressão de regime, adotado pelo Brasil, a sua razão de existir. Indubitável, pois, a situação caótica do sistema prisional do Estado de Santa Catarina, a qual impõe a afirmativa de que existe - sim! - omissão dos entes federados no 
trato da questão e que as medidas até então tomadas se mostraram inoperantes, caindo por terra o principal fundamento da sentença, a qual é de ser reformada, para que se reconheça a procedência do pedido de criação e implementação de vagas nos regimes fechado e semiaberto no Estado de Santa Catarina. Apelações providas.

Na situação acima exposta, a Defensoria Pública da União moveu ação civil pública em face do Estado de Santa Catarina e da União, objetivando que os Réus fossem condenados a adotarem medidas administrativas necessárias para a criação de vagas destinadas ao recolhimento de presos nos regimes fechado e semiaberto no âmbito do sistema carcerário do Estado de Santa Catarina, além de criar previsão orçamentária para implementação dessas medidas.

Ainda, alternativamente, requereu a Defensoria Pública que os presos condenados à pena de reclusão a ser cumprida em regime semiaberto e que estejam cumprindo pena em estabelecimentos penais de regime fechado por falta de vagas, aguardem a criação das referidas vagas em regime domiciliar.

O Estado de Santa Catarina alegou no mérito ser materialmente impossível a criação imediata de mais de 4.000 (quatro mil) vagas no sistema prisional e que o Estado de Santa Catarina, o qual já estaria se empenhando para solucionar o problema da superlotação das unidades de forma administrativa. Da mesma forma, a União argumentou a impossibilidade jurídica do pedido, por afronta ao princípio da separação dos poderes, uma vez que o Poder Judiciário deve limitar-se à apreciação da legalidade dos atos administrativos, não podendo ingerir no direcionamento do orçamento público.

A sentença julgou improcedente o pedido, sob o fundamento de que não foi possível, com os dados informados pela Defensoria Pública da União, concluir que efetivamente a abertura de novas vagas solucione por si os graves problemas do sistema prisional em Santa Catarina (outros fatores são igualmente significativos em seu instável equilíbrio), numa situação dinâmica como a que acaba de ser caracterizada (e contrastada em elementos estatísticos), é inviável a ingerência específica mediante atuação judicial. 
O Ministério Público Federal, inconformado com a sentença, apelou alegando que a análise minuciosa dos dados utilizados como base para a improcedência da ação coletiva demonstra que há no sistema 16.311 presos, enquanto o Estado disponibiliza tão somente 9.806 vagas, ou seja, apenas $60 \%$ da necessidade real, o que demonstra a situação caótica vivenciada pelo sistema penitenciário no Estado de Santa Catarina, o que comprova a omissão estatal. Pleiteou ao Tribunal a implementação das medidas necessárias, conforme a inicial.

O Tribunal Regional Federal da $4^{\mathrm{a}}$ Região acolheu a pretensão da ação civil pública, anulando a sentença.

É possível conclui, nesse julgado, que foi expressamente identificada a omissão estatal em política pública e a devida interferência judicial, provocada pela atuação de ação civil pública, movida pela Defensoria Pública da União, em Santa Catarina.

O segundo caso prático refere-se ao direito difuso da educação nas escolas, julgado pelo Tribunal de Justiça do Distrito Federal e Territórios:

DIREITO CONSTITUCIONAL E ADMINISTRATIVO. AÇÃO CIVIL PÚBLICA. DIREITO À EDUCAÇÃO. GARANTIA CONSTITUCIONAL E DEVER DO ESTADO. ESCOLA COM INFRAESTRUTURA PRECÁRIA. RECONSTRUÇÃO. NECESSIDADE. OMISSÃO ESTATAL. INTERVENÇÃO DO PODER JUDICIÁRIO. POSSIBILIDADE. CONVENIẾNCIA E OPORTUNIDADE DA

INAPLICABILIDADE. OFENSA AO PRINCÍPIO DA SEPARAÇÃO DOS PODERES. INEXISTÊNCIA. RECURSOS ESCASSOS. METAS PRIORITÁRIAS.

1. A Constituição Federal sagrou a educação como sendo direito e garantia fundamentais (art. $6^{\circ}$, caput). E, preceituou no artigo. 205, caput, que a educação é "direito de todos e dever do Estado". Logo, não se pode dar conformação à omissão estatal por esse não promover a reconstrução de escola que não possui infraestrutura adequada para oferecer uma educação de qualidade nos termos determinados pela Carta Política.

2. Os direitos da criança, do jovem e do adolescente, a receber uma educação de qualidade, em sendo prioridade absoluta, não podem estar limitados por um juízo de conveniência e oportunidade da Administração Pública, cabendo ao Poder Judiciário, nos casos de 
omissão por parte do Poder Executivo, intervir de modo a conferir efetividade à Constituição.

3. Não há que se falar em violação ao Princípio da Separação dos Poderes, uma vez que os atos do Poder Executivo estão submetidos ao controle de legalidade efetuado pelo Poder Judiciário.

4. É certo que os recursos do Estado são limitados e escassos, contudo é imprescindível o estabelecimento de metas prioritárias pelo Administrador Público, observando-se os fundamentos e objetivos da Carta Magna.

5. Recurso de apelação e remessa oficial conhecidos e não providos.

Neste segundo caso, o Ministério Público do Distrito Federal e Territórios - MPDFT moveu ação civil pública contra o Distrito Federal buscando a reforma da Escola Classe 01 do Riacho Fundo I, situada na QS 04, Área Especial 2/4, Lote A, que conta com graves problemas hidráulicos e elétricos, além de ser inacessível a pessoas com deficiência, apesar de haver dois alunos portadores de necessidades especiais.

A sentença julgou procedente o pedido e condenou o Distrito Federal à obrigação de fazer consistente na reconstrução da referida Escola, no prazo de 1 ano a contar do trânsito em julgado da decisão, com incidência de multa diária, em caso de descumprimento, no valor de $\mathrm{R} \$ 5.000,00$ (cinco mil reais).

Como fundamento, o Magistrado invocou a Constituição, que elevou a educação a direito e a garantia fundamentais (art. $6^{\circ}$, caput) e fixou a responsabilidade do Estado por meio do art. 205, caput: "educação é direito de todos e dever do Estado".

Inconformado, o Distrito Federal apelou, alegando a impossibilidade de reconstrução da escola no prazo fixado na sentença, o que não foi acolhido pelo Tribunal de Justiça do Distrito Federal e Territórios, que manteve a sentença.

Novamente, denota-se a ação civil pública provocando o judiciário, que age no sentido de intervir na política pública, garantindo os interesses difusos, no caso em análise, o da educação e da acessibilidade aos portadores de necessidades especiais.

Por fim, verifica-se uma situação referente a direito ambiental, com decisão do Tribunal de Justiça de Santa Catarina, que reformou a sentença do Juiz da Comarca de Florianópolis: 
AÇÃO CIVIL PÚBLICA. APELAÇÕES CÍVEIS. MEIO AMBIENTE. (...) PRELIMINARES RECHAÇADAS. LICENCIAMENTO AMBIENTAL. DIFERENÇA ENTRE "RESTINGA" E "VEGETAÇÃO DE RESTINGA". CARACTERIZA ÁREA DE PRESERVAÇÃO PERMANENTE, NOS TERMOS DA LEI, APENAS A RESTINGA, COMO FIXADORAS DE DUNAS OU ESTABILIZADORAS DE MANGUES. INTERPRETAÇÃO LITERAL DO ART. $4^{\circ}$, VI, DA LEI FEDERAL N. 12.651/2012 (NOVO CÓDIGO FLORESTAL). SENTENÇA QUE IMPEDIU A CONCESSÃO DE LICENÇA AMBIENTAL, INDEPENDENTE DA EXISTÊNCIA OU NÃ̃ DO ACIDENTE GEOGRÁFICO "RESTINGA". DECISÃO REFORMADA. RECURSOS CONHECIDOS E PROVIDOS.

Para os efeitos da Lei Federal n. 12.651/2012, entende-se por restinga: "depósito arenoso paralelo à linha da costa, de forma geralmente alongada, produzido por processos de sedimentação, onde se encontram diferentes comunidades que recebem influência marinha, com cobertura vegetal em mosaico, encontrada em praias, cordões arenosos, dunas e depressões, apresentando, de acordo com o estágio sucessional, estrato herbáceo, arbustivo e arbóreo, este último mais interiorizado" (art. $\left.3^{\circ}, \mathrm{XVI}\right)$.

Considera-se Área de Preservação Permanente, em zonas rurais ou urbanas, as restingas, como fixadoras de dunas ou estabilizadoras de mangues (art. $4^{\circ}$, VI).

"A ação civil pública se sustenta no voto vencedor do Min. Herman Benjamin, nos autos do REsp. n. 945.898-SC, que indo além do que discutido, pois a hipótese versada contemplava restinga fixadora de dunas, fez ver, com o brilhantismo que lhe é próprio, e pelas convicções que sustenta, que já seria momento de se ampliar, para fins jurídicos, o que se deve entender por restinga, fugindo a redoma de que só seria área de preservação permanente quando protetora de dunas ou estabilizadora de mangues. Entretanto, é a lei que assim quer (art. $2^{\circ}$, f da Lei $4.771 / 65$; art. $3^{\circ}$, XVI, da Lei 12.651/2012; art. $2^{\circ}$ da Lei 11.428/2006), cumprindo ao julgador se lhe dê concretude enquanto não alterada, caso contrário seria transformar o processo judicial em fonte legiferante." (TJSC, Órgão Especial, Agravo ( $\$ 3^{\circ}$ art. $4^{\circ}$ da Lei 8.437/92) em Pedido de Suspensão de Liminar n. 2014.028915-9/0001.00, da Capital, Relator Designado: Des. Cesar Abreu, j. 15.10.2014). 
A situação em cotejo diverge das anteriores em razão do entendimento do Tribunal de Justiça de Santa Catarina adotar postura de autocontenção, ou seja, limitar-se ao que diz a legislação, ainda que se tratem de direitos difusos - meio ambiente.

Em origem, trata-se de ação civil pública movida pelo Ministério Público de Santa Catarina em face da Fundação do Estado do Meio Ambiente - FATMA, requerendo que ela se abstivesse de conceder licença ambiental para qualquer corte e/ou supressão de vegetação de restinga, além de passar a considerar como área de preservação permanente qualquer local onde se apresente a vegetação de restinga, independente da existência ou não do acidente geográfico "restinga". O pedido se baseou em decisão do Superior Tribunal de Justiça no Recurso Especial no 945.898/SC com idêntico entendimento.

Em defesa, a FATMA afirmou que o conceito de restinga, para fins de preservação no Código Florestal, comporta tão somente a vegetação fixadora de dunas e estabilizadora de mangue, aliando assim o aspecto da flora (vegetação) com o geológico (dunas), trazendo um precedente jurisprudencial e legal - novo Código Florestal (Lei $\left.n^{\circ} 12.651 / 12\right)$.

A sentença julgou procedentes os pedidos formulados na ação civil pública, acolhendo os fundamentos lá contidos, o que ensejou recurso de apelação por parte da Fundação do Estado do Meio Ambiente.

O Tribunal de Justiça de Santa Catarina, por sua vez, adotou postura de autocontenção, entendendo que, não obstante esteja em pauta direito difuso de preservação do meio ambiente, a ação deve ser julgada improcedente, respeitando a vontade do legislador em restringir a vegetação a ser preservada, dando provimento ao apelo.

Deste caso, pode-se observar que a postura adotada pelos Magistrados e Tribunais nem sempre caminham em um mesmo sentido, apesar de serem, em maioria, proferidas decisões que buscam a garantia dos direitos difusos e coletivos com intervenção nas políticas públicas. Em síntese, essa postura não é absoluta e depende de fatores como o caso concreto, a abordagem do autor da ação civil pública e o entendimento do Magistrado acerca do assunto. 


\section{CONSIDERAÇÕES FINAIS}

Com este artigo, foi realizado levantamento bibliográfico e jurisprudencial, buscando verificar os fundamentos para legitimar as decisões judiciais em ação civil pública que versa sobre direitos difusos, coletivos em sentido estrito e individuais homogêneos, analisando a tendência das tomadas de decisão judicial neste âmbito.

Após o estudo dos conceitos sobre referidos interesses difuso, coletivo e individual homogêneo, da ação civil pública e seu mecanismo processual e material e, dos fundamentos sobre a intervenção judicial nas políticas públicas em ação civil pública, foram trazidas três jurisprudências relevantes no Brasil, como exemplo de entendimentos.

Com o conjunto das informações, conclui-se, em síntese, que a postura adotada pelos Magistrados e Tribunais nem sempre caminham em um mesmo sentido, apesar de serem, em maioria, proferidas decisões que buscam a garantia dos direitos difusos e coletivos com intervenção nas políticas públicas.

Isto é, a postura dos Magistrados em situações de violação dos direitos difusos e coletivos não possui tendência única e depende de fatores como o caso concreto, a abordagem do autor da ação civil pública e o entendimento do Magistrado acerca do assunto.

\section{REFERÊNCIAS DAS FONTES CITADAS}

Access to Justice: The Worldwide Movement to Make Rights Effective. E General Report, Milano: Giuffrè Editore, 1978. Traduzido para o português por Northfleet, Elles Graice. Acesso à Justiça - Porto Alegre: Sérgio Antônio Fabris Editor, 1988.

Acórdão n. 871693, 20110111864723APO, Relator: GISLENE PINHEIRO, Revisor: J.J. COSTA CARVALHO, $2^{\text {a }}$ TURMA CÍVEL, Data de Julgamento: 27/05/2015, Publicado no DJE: 08/06/2015. Pág.: 97.

BRANDÃO, Paulo de Tarso. Ações Constitucionais: "Novos" Direitos e Acesso à Justiça. 2. ed. Florianópolis: Oab/sc, 2006.

BRASIL. Constituição da República Federativa do Brasil (1988), de 05 de outubro de 1988.

BRASIL. Lei $\mathrm{n}^{\circ}$ 8.078, de 11 de setembro de 1990. Dispõe Sobre a 
Proteção do Consumidor e dá Outras Providências.. Brasília, DF.

CALDEIRA, Adriano Cesar Braz. Aspectos processuais das demandas coletivas. São Paulo: Rideel, 2006.

COMPARATO, Fábio Konder. Novas funções jurisdicionais no Estado moderno. RT, n. 614, 1996.

FERRAZ, Antônio Augusto Mello de Camargo, MILARÉ, Édis, JUNIOR, Nelson Mery. A ação civil pública e a tutela jurisdicional dos interesses difusos. São Paulo: Saraiva, 1984.

GRINOVER, Ala Pellegrini (coord.). A tutela jurisdicional dos interesses difusos. Revista Forense, n. 286, p. 76.

MANCUSO, Rodolfo de Camargo. Interesses Difusos: Conceito e Legitimidade. 7. ed. São Paulo: Editora dos Tribunais, 2011.

MARINS, James. Ações Coletivas em Matéria Tributária. in, Revista de Processo, n. 76, p. 97/105, 1985.

MAZZILLI, Hugo Nigro. Defesa dos interesses difusos em juízo: meio ambiente, consumidor, patrimônio cultural, patrimônio público e outros interesses. 23. ed. São Paulo: Saraiva, 2010.

NALINI, José Renato. O juiz e a proteção dos interesses difusos. Revista da Procuradoria Geral do Estado de São Paulo, 1992, RT 680, p. 60.

RE 163.231-3-SP, STF Pleno, Informativo STF, 62, e DJU, 29-06-01, p. 55; RE 332.545-SP, $1^{\text {a }}$ T., STF, Informativo STF, 398.

SMANIO, Gianpaolo Poggio. Interesses Difusos e Coletivos: Estatuto da Criança e do Adolescente, Consumidor, Meio Ambiente, Improbidade Administrativa, Ação Civil Pública e Inquérito Civil. 6. ed. São Paulo: Atlas, 2004. (Fundamentos jurídicos).

SOUZA, Motauri Ciocchetti de. Ação Civil Pública e Inquérito Civil. São Paulo: Saraiva, 2001.

TRF4, AC 5001883-22.2013.4.04.7200, TERCEIRA TURMA, Relator CARLOS EDUARDO THOMPSON FLORES LENZ, juntado aos autos em 29/05/2014.

VIGLIAR, José Marcelo Menezes. A tutela dos interesses metaindividuais. 2. ed. São Paulo: Cpc, 1998.

TJSC, Apelação Cível n. 2014.079082-7, da Capital, rel. Des. Júlio César Knoll, Terceira Câmara de Direito Público, j. 28-07-2015. 
